able. However, sanitation was a problem, with a shortage of toilets and latrines. Because bottled water was distributed, water-borne diseases were not an issue. Some people complained that food and other relief goods were not distributed in a balanced way.

Conclusions: Respiratory disease needs to be a primary concern, followed by psychological problems. More latrines should be made available. Recovery from the acute to the sub-acute phase was fairly good, with the exception of psychological stress. The probability of spreading infectious disease was low. Keywords: acute phase; earthquake; Iran; Japan Disaster Relief; refugee; respiratory disease; stress; sub-acute phase; survey Prehosp Disast Med 2005:20(2)::59-s70

\section{Casualty and Damage Estimation-Accuracy and What Affects It}

M. Hopmeier; ${ }^{1}$ C. Lee; ${ }^{1}$ T. Davis; ${ }^{2}$ E. Noji ${ }^{2}$

1. Unconventional Concepts, Inc., USA

2. USA

At the onset of a disaster, whether it is natural or humanmade, the general public and research professionals first learn details from the news media. In this age of CNN, the Internet, and e-mail, mass distribution of information through news wires is the staple source of information, good or bad, accurate or inaccurate. Casualty estimates are useful pieces of data because they provide an indicator of the magnitude of the disaster, and include the number dead-on-scene (DOS), critically wounded, number admitted to local hospitals, number of injured/exposed, and the total number dead, including those who have died-in-hospital (DIH). Casualty estimates also can include the number of children and elderly who have been injured or killed, or the casualties for other subsets of the population such as emergency workers. These estimates are vital for assessing the extent of a disaster, and ultimately, the level of resources that need to be applied.

This presentation examines the accuracy of reports versus final accepted results. Not only does this study try to examine how long it takes to arrive at a confirmed number of dead and injured/exposed, but also the deviation of numbers and their related causes. For example, in the original reports of those killed in the 11 September 2001 attacks, a reported 30,000 persons were killed in both World Trade Center towers combined. A year and a half later, the true estimate was closer to 3,000, an estimate one-tenth of what was previously predicted. This same type of disparity is common throughout many disasters, both human-made and natural.

This study also will serve to explain and discuss why casualty figures deviate and what might influence their ultimate reporting to the public, such as the number of missing individuals, chaos of the scene, lack of centralized reporting authorities, wide region of land affected making victims untraceable, political pressure, and unknown census/population figure estimates. Conclusions then will be drawn and methods will be provided that may be used to assess damage at the onset of an incident more accurately. Keywords: assessments; casualties; data; disaster; estimates; figures; human-made; natural Prehosp Disast Med 2005;20(2):s70

\section{Linking Disaster Preparedness and Sustainable Development \\ T.D. Banerjee}

West Bengal Voluntary Health Association, India

Introduction: Emergency planning is radically different from planning under normal circumstances. It must be quick and fit for the situation. Planning can be results-oriented, cost-effective, economic, timely, people-oriented, and rapid, if preparedness initiatives are taken earlier. The Indian subcontinents are vulnerable to droughts, floods, cyclones, sea surges, earthquakes, avalanches, forest fires, and man-made events, like traffic crashes, fires, chemical accidents, and violence. The West Bengal Voluntary Health Association (WBVHA) has been working in the state of West Bengal, India for $>30$ years in the health and development field with active cooperation and involvement of non-governmental organizations (NGOs), community-based organizations (CBOs), Panchayati Raj Institutions (PRIs), government, and professional national and international agencies.

Disasters commonly inhibit the development of the community and the country as a whole. There are not any alternatives by which one can avoid potential "hazards", but one can avoid "disasters" by implementing effective means of "preparedness". The WBVHA is one of the primary players in the state of West Bengal, promoting communitybased, disaster preparedness for sustainable development, and believe it is necessary to link "disaster preparedness" with "sustainable development".

Through disaster preparedness, several initiatives, such as vulnerability assessment coordination, cooperation, planning, mitigation, institutional framework, information systems, resource base, warning systems, response mechanisms, and education. All these exercises help people to be united, task-oriented, and alert. This is the correct time to link the preparedness initiatives into sustainable development by means of linking development into vulnerability reductions, making room for agriculture, small-scale industries, and housing loss reductions. Also, efforts to assist people becoming organized and action-oriented will minimize the damages. Making people organized to face disasters, will reduce the loss of life and property. Well thought-out initiatives will help overcome the losses of agriculture and crop failure. All development activities, especially the buildings and other infrastructures must be earthquake and hazard resistant. Education at all levels must be complete so that every person can take appropriate measures at the time of an emergency without becoming dependent. The rescue and other services should be strong enough to manage the situation within very little loss. Rehabilitation and other planning must incorporate so that the suffering and economic loss can be reduced.

Conclusion: Well-organized disaster preparedness initiatives can bring a successful, result-oriented, sustained development by which the people will be the ultimate beneficiaries. The community must be involved in the planning and decision-making processes to incorporate Disaster Preparedness initiatives into sustainable development.

Keywords: disaster preparedness; emergency planning; India; West Bengal Voluntary Health Association (WBVHA)

Prehosp Disast Med 2005;20(2):s70 